\title{
WNT-targeted compound and phytoestrogen promoted cardiogenic differentiation of human induced pluripotent stem cells (hiPSCs) in vitro
}

\author{
Javad Kazemi ${ }^{1}$, Hosein Shahsavarani ${ }^{2,3, *}$, Parviz Pakzad ${ }^{1}$, Mohammadali Shokrgozar ${ }^{2,4, *}$ \\ ${ }^{1}$ Department of Cellular and Molecular Biology, Faculty of Biological Sciences, North Tehran Branch, Islamic Azad University, 1651153311 Tehran, \\ Iran \\ ${ }^{2}$ Department of Cell and Molecular Sciences, Faculty of Life Science and Biotechnology, Shahid Beheshti University, 1983963113 Tehran, Iran \\ ${ }^{3}$ Laboratory of Regenerative Medicine and Biomedical Innovation, Pasteur Institute of Iran, 1316943551 Tehran, Iran \\ ${ }^{4}$ Department of National Cell Bank, Pasteur Institute of Iran, 1316943551 Tehran, Iran \\ *Correspondence: hosein.shahsavarani@gmail.com (Hosein Shahsavarani); mashokrgozar@pasteur.ac.ir (Mohammadali Shokrgozar) \\ Submitted: 14 April 2021 Accepted: 2 July 2021 Available online: 23 August 2021 Published: 9 February 2022
}

\begin{abstract}
Background and objectives: Despite the advances made in the prevention and treatment of cardiovascular diseases (CVD) in the last decade, they are still the leading cause of death in males at the rate of $50 \%$ worldwide. Considering the protective role of estrogen to decrease CVD rates in young females, it was suggested that using hormone therapy can be considered to improve heart regeneration. Using in vitro induced pluripotent stem cells (iPSCs) has become one of the most significant tools in CVD treatment in both genders. We design a novel optimal protocol for the differentiation of iPSCs to cardiomyocytes which may be valuable for CVD treatment in men. Methods: Human iPSCs were initially cultivated on mouse embryonic fibroblasts and then, transferred to a specific culture medium for differentiation process. In vitro differentiation of iPSCs into cardiomyocytes was induced at three phases on RPMI-1640 medium including CHIR99021 $(5 \mu \mathrm{M})$ on days $0-3$, BMP4 $(20 \mathrm{ng} / \mathrm{mL})$, and bFGF $(100 \mathrm{ng} / \mathrm{mL})$ on days 3-5, $10 \mu \mathrm{M}$ of XAV939 on 6-8, and phytoestrogen + ascorbic acid on days 8-13. Scanning electron microscopy and Real-time PCR using specific primers were applied to confirm produced cardiomyocytes. Results: We found that the simultaneous use of small chemical molecules such as CHIR99021 and XAV 939, growth factors, such as BMP4, bFGF, and herbal-derived phytoestrogen from red clover could efficiently differentiate hiPSCs from the mesoderm and cardiomyocytes after 13 days. Using phytoestrogen increased the induction of cardiac markers including cTnT and GATA-4 in a shorter time; consequently, the proposed formulation has the potential to be used in developing a novel approach for cardiac repair or regeneration. Conclusion: Presented data indicated that the serial use of XAV939 and phytoestrogen at different times and stages can successfully induce cardiogenesis from hiPSCs. Thus, the proposed approach can be used for improved translational strategies for cardiac regeneration with fewer side effects.
\end{abstract}

Keywords: Cardiac regeneration; hiPSCs; Phytoestrogen; Small molecules

\section{Background}

Over the last few decades, cardiovascular disease (CVD) was considered the major leading cause of mortality and morbidity worldwide [1,2]. It led to about 17 million deaths in 2012 [3]. Myocardial infarction (MI) is the most common type of heart failure characterized by a remarkable loss of the number of functional cardiomyocytes which affect beating and eventually pumping blood to the whole body. Despite the presence of multiple treatments for CVDs such as surgery and pharmaceutical therapies, they are still challenging, and other approaches were proposed to reduce the rate of side effects caused by these techniques. Owing to the fact that adult hearts have a slight capacity to regenerate themselves, the heart regeneration methods such as cardiomyocyte transplantation to restore lost cells and heal the damaged tissues, have become a novel approach for MI treatment $[4,5]$.
Before puberty, the ratio of left ventricular (LV) mass to body weight is higher in boys than in girls. One year after birth, the mitotic division of normal cardiomyocytes stops, and the cardiomyocytes begin to increase in volume (hypertrophy) relative to the number of cells. This left ventricular-sized hypertrophy in men has increased CVD risk compared to women [6]. While, CVD is prevalent in young women, epidemiological results showed that postmenopausal women have a somewhat similar rate of heart disease to men [7]. Therapeutic response to some cardiovascular-related diseases such as aortic stenosis is better in women than in men and also transcriptomic results have also shown that fibrosis and inflammation are present in men but very low in women [8]. Studies represented that the reason to protect premenopausal women from CVD is the presence of female hormone estrogen which is much lower in the blood of postmenopausal and oophorectomy cases similar to men $[9,10]$. Both men and women produce the estrogen hormone; however, the amount of estrogen in 
women is much higher than in men. In women, most of the estrogen hormone is produced in the ovaries and pituitary gland, but in men, the amount of this hormone is less, and it is secreted from the testicles. Various reports showed that estrogen plays a role to protect the heart in different ways [11]. The estrogen hormone, as a ligand, binds to its receptor $(\mathrm{ER} \alpha$ and $\mathrm{ER} \beta)$. Daidzein and genistein are natural compounds which structurally belong to a class of compounds called isoflavones. They serve as phytoestrogens and are abundant in various edible plants such as soybeans and red clover. Phytoestrogens, like estrogen, bind to both $\operatorname{ER} \alpha$ and $\operatorname{ER} \beta$; however, they bind to $\operatorname{ER} \beta$ with greater affinity.

Nowadays, pluripotent stem cells (PSCs), encompassing embryonic stem cells (ESCs) and induced pluripotent stem cells (iPSCs) have become the most promising sources for drug discovery and tissue regeneration [12-15]. These cells are capable of uncontrolled proliferating in vitro while maintaining the potential to differentiate into three germ layers. Various methods were developed for reprogramming and producing iPS cells from somatic cells, but due to using multiple growth factors or recombinant proteins or inducers, these techniques are relatively expensive [1618]. Furthermore, the use of iPSCs in the treatment of cardiac diseases is better than ESCs due to the lack of socialethical issues and immune rejection [19-21]. Moreover, induced pluripotent stem cell-derived cardiomyocytes (iPSC$\mathrm{CMs}$ ) were used for heart remodeling after ischemic disease [16,22]. Cardiac development consists of a complex network of signal transduction pathways and transcription factors which work in a combinatorial manner.

WNTs/Nodal, bone morphogenetic proteins (BMPs) and fibroblast growth factors (FGFs) are some of the most important specialized cardiac signaling pathway factors [23]. Canonical WNT/ $\beta$-catenin signal transduction pathway is one of the most important signaling pathways which serves as a double-edged sword, and plays an important role in the heart development and differentiation from PSCs. In this pathway, glycogen synthase kinase- $3 \beta$ (GSK $3 \beta$ ) plays strategic roles in different physiological processes such as the development, apoptosis, and cell cycle, particularly in cardiac cells $[24,25]$. Short-term induction of WNT signaling pathway maintains pluripotency, while prolonged induction of WNT signaling pathway by small molecules leads to differentiation of pluripotent stem cells to mesoderm derivatives [26,27]. Recent evidence has recommended using small molecules in various processes, such as in vitro cell differentiation and reprogramming. For example, it has been reported that inhibition of GSK $3 \beta$ by chemical small molecule inhibitors, such as CHIR99021, BIO, CHIR98014, SB-216763, and AR-A014418 induce apoptosis of cancer cells in mice [28,29]. CHIR99021 induces efficient differentiation of cardiomyocytes via inhibition of GSK $3 \beta$ factor [30,31]. Nevertheless, various factors must be considered to determine the fate of iPSC-CMs differen- tiation, including binary (inhibition and induction) modulation of WNT signaling, concentrations of GSK $3 \beta$ inhibitors (e.g., CHIR99021 as the WNT inducer and IWR1 as WNT inhibitor), and 3-dimensional culture medium [32]. BMP and Activin A are also required for iPSC-CMs generation $[33,34]$.

Although hiPSC-CMs have recently been developed by different protocols using small molecules, other parameters, such as the maturation of hiPSC-CMs, morphology [35], reliance on consumption of glycolytic metabolism [36], and calcium handling [37] in a 3D substrate were optimized to produce cardiomyocytes that are similar to adult cardiac cells $[38,39]$. Estrogen was shown to play a very important role to maintain women's health and preventing many heart diseases [40]. Since the phytoestrogen has an estrogen-like function and binds to the same estrogen receptor $(\operatorname{ER} \alpha$ and $\beta$ ) [41], in this experiment, the animal estrogen-like plant estrogen compound was employed to induce cardiomyocyte differentiation in the late stage of process. This study was done to generate cardiomyocytes from hiPSCs using chemical small molecules and phytoestrogen, as a natural extract from red clover leaf to investigate the combination of using different concentrations of phytoestrogens and other small molecules in mesoderm and cardiac differentiation. Finally, the interaction of amino acids of p38MAPK protein with the genistein and electric charge distribution of genistein was evaluated by molecular docking methods that the purpose of this bioinformatics structural assay is to study the geometric structure of genistein in depth and use it as a therapeutic drug for the treatment of heart disease and to investigate the possibility of side effects on the heart.

\section{Materials and methods}

\subsection{Chemicals and reagents}

Human BMP4, Activin A, bFGF, and CHIR99021 were purchased from Applied Biological Materials (ABM) Inc, Richmond, BC, Canada, whereas XAV939, glutamine, and L-Ascorbic acid, were bought from FUJIFILM Wako Chemicals, Osaka, Japan. The hESC-qualified Matrigel (TM) (BD Biosciences, San Jose, CA, USA), mTESR1 (STEMCELL Technologies, Vancouver, BC, Canada), Fetal Bovine Serum (FBS) from Gibco, Thermo Fisher Scientific, Brasil, Triton X-100 (Sigma-Aldrich, Tokyo, Japan), phosphate-buffered saline (PBS) without $\mathrm{Ca}^{2+}$ and $\mathrm{Mg}^{2+}$ (Kiazist Corp, Hamedan, Iran), paraformaldehyde (SigmaAldrich), RPMI-1640 with L-Glutamine medium (FUJIFILM Wako Chemicals), and sodium L-lactate (SigmaAldrich), collagenase type 1 (FUJIFILM Wako Chemicals), Glycine, bovine serum albumin (BSA), Tween 20 (Merck), first and second antibody, $1 \mathrm{X}$ penicillin-streptomycin solution (Sigma-Aldrich), Dulbecco's Modified Eagle Medium (DMEM) containing 4.5 g/L D-glucose (Gibco), mitomycin C (Sigma-Aldrich), $70 \%$ ethanol, and $0.25 \%$ trypsin-EDTA (Bio idea) were used. Phytoestrogen was extracted from the 


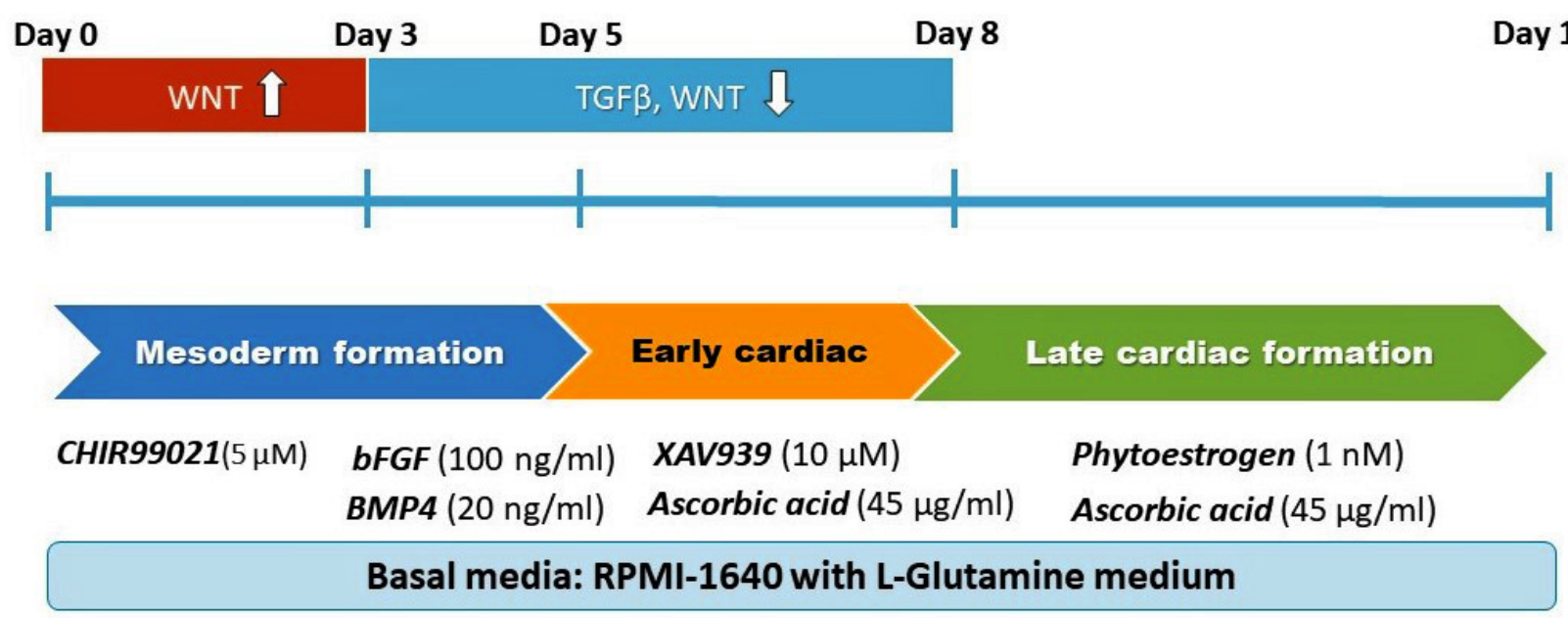

Fig. 1. Schematic representation of our cardiomyocyte differentiation approach.

leaves of Trifolium pratense, as explained in our earlier report [42].

\subsection{Mouse embryonic Fibroblasts (MEFs) isolation and inactivation}

The following procedure was used: Harvest embryos from pregnant female mice 12.5 days. Thoroughly soak the mice fur with $70 \%$ ethanol. Gently cut the mice's skin with scissors. Put the mice in one petri dish containing $10 \mathrm{~mL}$ $0.25 \%$ trypsin-EDTA, then using forceps and scissors, lift up the skin, and cut the uterine horn. Separate all embryos by slicing the region between them then transfer the embryos to a new petri dish covered by PBS to remove the blood. Cut off the head and tear out the red tissues, such as the liver and heart of embryos and then, transfer the rest of the embryos in a petri dish containing $0.25 \%$ trypsinEDTA. Therefore, using a razor blade to mince the tissue of the embryo into pieces of 1-2 mm. Pipet up and down several times and then place the petri dish in tissue culture incubator with $37^{\circ} \mathrm{C}$ for $10 \mathrm{~min}$. At last, transfer single and cluster cells to T75 flasks containing 15-20 mL MEF culture medium (DMEM + 10\% FBS). Grow MEFs until confluent $80-90 \%$ after 1 day and then, to inactivate MEF, add $10 \mu \mathrm{g} / \mathrm{mL}$ Mitomycin $\mathrm{C}$ per $1 \mathrm{~mL}$ medium, return flasks to the incubator for $2-3 \mathrm{~h}$. subsequently, rinse the flask twice with 15-20 mL PBS.

\subsection{Cultivation of human iPSCs}

A lentiviral derived iPSC line from human dermal fibroblasts was previously generated in our laboratory. The cells were initially cultivated on mouse embryonic fibroblasts (MEFs) followed by passage onto Matrigel-coated plates in mTeSR1 medium until they reached about $90 \%$ confluency.

\subsection{In vitro differentiation of iPSCs into cardiomyocytes}

The process of cardiomyocyte differentiation from iPS cells is shown in Fig. 1. hiPS cells were transferred to RPMI-1640 basal medium containing $45 \mu \mathrm{g} / \mathrm{mL}$ L-Ascorbic acid and $2 \mathrm{mM}$ glutamine and B27. Small molecules and growth factors including CHIR99021 (5 $\mu \mathrm{M})$ on $0-3$ days, BMP4 (20 ng/mL), and bFGF (100 $\mathrm{ng} / \mathrm{mL}$ ) on days $3-5$, were added to the cells culture medium to induce iPS differentiation to mesoderm. Cells were incubated for $24 \mathrm{~h}$ at $37{ }^{\circ} \mathrm{C}$ and then, kept in this medium with CHIR99021 (5 $\mu \mathrm{M})$ for $24 \mathrm{~h}$. Next, the culture medium was replaced with a similar basal RPMI-1640 medium containing $10 \mu \mathrm{M}$ of XAV939. Cells were kept in this basal culture medium for 3 days and then, the medium was replaced with cardiac enrichment medium and RPMI-1640 medium with $3 \mathrm{mM}$ sodium L-lactate and without glucose. Afterward, cells were kept in a culture medium containing herbal extract phytoestrogen for 6 days, and after the enrichment phase, the medium was switched back to basal medium containing RPMI-1640, glutamine, and B27.

\subsection{Real-time PCR}

Total RNA was extracted using RNX-Plus (SinaClon; RN7713C) Kit. After extraction process, a Nanodrop ND1000 spectrophotometer (Thermo Sci., Newington, NH, USA) method was applied to estimate the quantity and quality of extracted RNAs. Total RNA $(1 \mu \mathrm{g})$ was reverse transcribed to cDNA using Easy cDNA Synthesis Kit (Pars Tous Biotech, Mashhad, Iran) using the following conditions; $95^{\circ} \mathrm{C}$ for $2 \mathrm{~min}$; followed by 34 cycles of $94{ }^{\circ} \mathrm{C}$ for $30 \mathrm{~s}, 60^{\circ} \mathrm{C}$ for $30 \mathrm{~s}$, and $72{ }^{\circ} \mathrm{C}$ for $45 \mathrm{~s}$; followed by a single cycle of $72{ }^{\circ} \mathrm{C}$ for $5 \mathrm{~min}$ and then, normalized based on its OD. Primers were purchased from the Macrogen online oligo order system, South Korea. Applied Biosystems 7500 
Table 1. Primer sequences of cardiomyocytes specific genes.

\begin{tabular}{lccc}
\hline Primer/sequence & Product length $(\mathrm{bp})$ & Annealing temperature $\left({ }^{\circ} \mathrm{C}\right)$ & $\mathrm{GC} \%$ \\
\hline cTnT & 166 & & 50 \\
F-TTCACCAAAGATCTGCTCCTCGCT & & 64.11 & 50 \\
R-TTATTACTGGTGTGGAGTGGGTGTGG & 120 & 64.34 & 47.62 \\
\hline GATA4 & & 59.12 & 50 \\
F- TAGACCGTGGGTTTTGCATTG & & 59.58 & 50 \\
R-CATCCAGGTACATGGCAAACAG & 102 & & 61.11 \\
\hline Col1A1 & & 55.69 & \\
F-ACGAAGACATCCCACCAA & & 60.73 & 57.89 \\
R-CGTTGTCGCAGACGCAGA & 178 & & 57.89 \\
\hline GAPDH & & 58.84 & 58.45 \\
F-ACCCACTCCTCCACCTTTG & & & 50 \\
R-CTCTTGTGCTCTTGCTGGG & & & \\
\hline
\end{tabular}

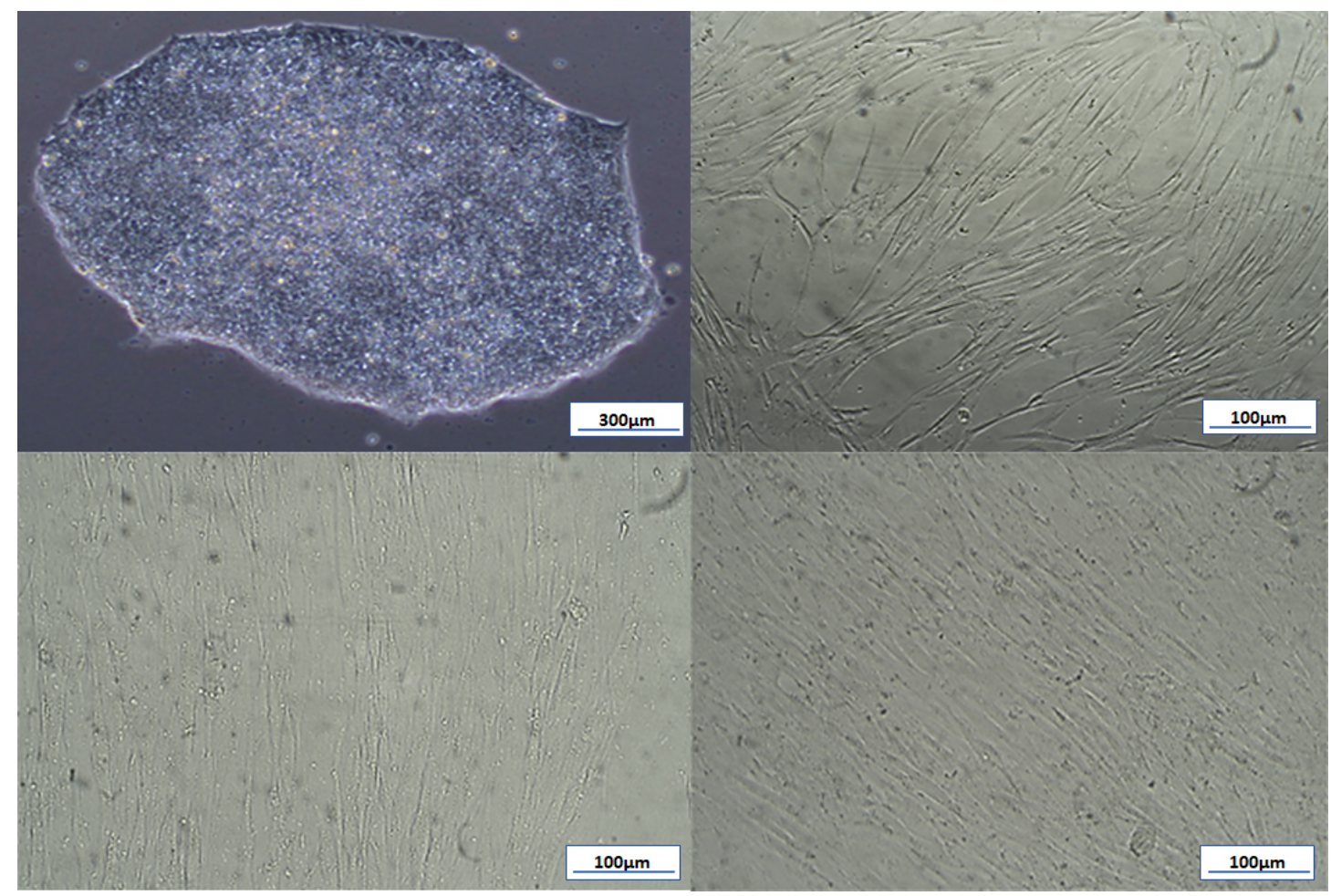

Fig. 2. Slight Changes in cell morphology during differentiation process using three distinct treatments. (A) hiPSCs $(100 \times)$. (B) Differentiated cells using cocktail CHIR99021, bFGF and BMP4 (40×). (C) Differentiated cells using XAV939 (40×). (D) Differentiated cells using phytoestrogen $(40 \times)$.

Fast Real-Time PCR thermocycler System and cyber green Takara master mix Kit (Takara Bio Inc., Shiga, Japan) in 34 cycles were applied based on manufacturer's instructions using $20 \mu \mathrm{L}$ reaction volumes for amplification. Primer sequences are shown in Table 1.

\subsection{Immunocytochemistry}

First, the culture medium is discarded and the plate is washed with PBS 1X. then, add enough 4\% paraformaldehyde (PFA) to the plate so that it covers only the surface of the plate. Incubate the plate for $3 \mathrm{~min}$ at room temperature. Then, discard the PFA and rinse well with PBS 1X. to transfer and penetrate the antibody into the cytosol, the cells were placed in buffer conditions containing $0.25 \%$ Triton X100 for $3 \mathrm{~min}$. After $3 \mathrm{~min}$ of incubation, the cells were washed three times for 5 min with PBS 1X. In the next step, blocking and staining should be done with the blocking buffer and primary antibody, respectively. The blocking buffer contains $22.52 \mathrm{mg} / \mathrm{mL}$ glycine in PBST (PBS + 0.1\% Tween 20), 1\% bovine serum albumin (BSA). Mouse anti- 

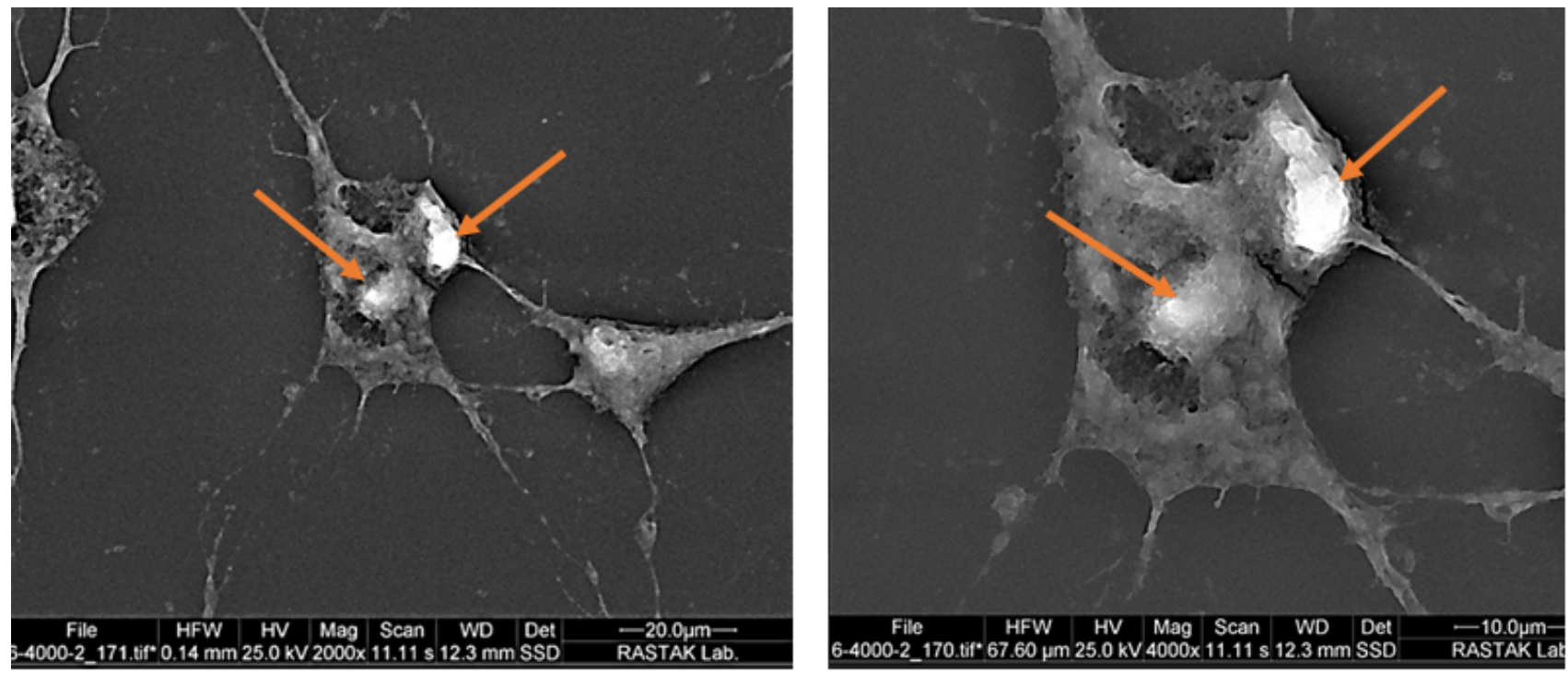

Fig. 3. Scanning electron microscopic images of differentiated cells. As shown in $2000 \times$ and $4000 \times$ magnifications, network connections and double nuclei (shown with two orange arrows) were seen in the cells showed efficient differentiation (Scale bare; $20 \mu \mathrm{m}$ and $10 \mu \mathrm{m})$.

rabbit $\alpha$-actinin primary antibody and secondary antibodies Alexa Flour 488 and 570 gout-anti mouse were purchased from sigma Aldrich. The samples were then incubated with BSA and primary antibody at $4{ }^{\circ} \mathrm{C}$ overnight. Subsequently, Alexa 488 fluorochrome-conjugated goat antimouse secondary antibody was included and incubated for $1-2 \mathrm{~h}$ at RT in the dark situation. Finally, plates were observed by fluorescent microscope (INV100-FL-BEL Engineering, Monza, ITALY).

\subsection{Scanning electron microscopy}

Before scanning electron microscopy (SEM) (performed in Partorayan Rastak Lab, Tehran, Iran, FEI ESEM QUANTA 200 microscopy, FEI Co., Hillsboro, OR, USA), specimens were prepared, completely dehydrated, and dried. Furthermore, cells should be rinsed with PBS thrice and fixed with a combination of glutaraldehyde $4 \%$ and paraformaldehyde $4 \%$ in $\mathrm{pH} 6.9$ for $1-2 \mathrm{~h}$ at room temperature. Then, ethanol series for critical point drying was done to obtain pictures with better resolution. Samples were coated with gold before examination to increase electron detection and surface scanning.

\subsection{Molecular docking methods}

As the inhibitor of WNT pathway, the molecular geometric structure of genistein was done using Chemoffice 18.0 software (CambridgeSoft Corporation, Cambridge, MA, USA). The optimized structure of molecule was plotted using Gaussian 03 software (The University of Cambridge, Cambridge, UK). The optimization of molecules at the highest level was performed using the density functional theory (DFT) method based on B3LYP calculations and the $6-311++\mathrm{G}(\mathrm{d}, \mathrm{p})$ method. It was performed for
6 computational runs, and each computational run was performed with 200 rounds of computational convergence to solve the Schrodinger equation. Then, the molecular electrostatic potential (MEP) graph was utilized to assess the electronic properties of the genistein molecular structure. Subsequently, the interactions between the genistein molecule and p38MAPK protein were analyzed and evaluated by Molegro Virtual Docker (MVD) software (QIAGEN, Hilden, Germany). The input of Gaussian 03 software was done via Gauss view 6 software (The University of Cambridge, Cambridge, UK), and the output of Gaussian 03 software was done via Gauss view 6 and GaussSum software (The University of Cambridge, Cambridge, UK). Docking output was done with MVD Viewer software. The biological simulation was performed with SwissADME free web tool.

\section{Results}

Using current methods to differentiate iPSCs into cardiomyocytes is limited by some challenges and problems such as low efficiency and reproducibility. Regulation of cardiomyocyte specificity by targeting gene expression in pluripotent stem cells is the result of interaction among various signaling pathways at different stages of evolution [43]. It means that signal transduction pathways mechanistically have several sequential or perhaps synergistic effects on signaling cascades, and ultimately increase the expression of cardiomyocyte markers such as cardiac troponin T (cTnT), sarcomeric $\alpha$-actinin protein, and GATA4 $[32,44]$. The inhibition of interactions among key signaling pathways using chemically and naturally small molecules at the precise time and optimal concentration can be a revolutionary approach to improve the differentiation of car- 

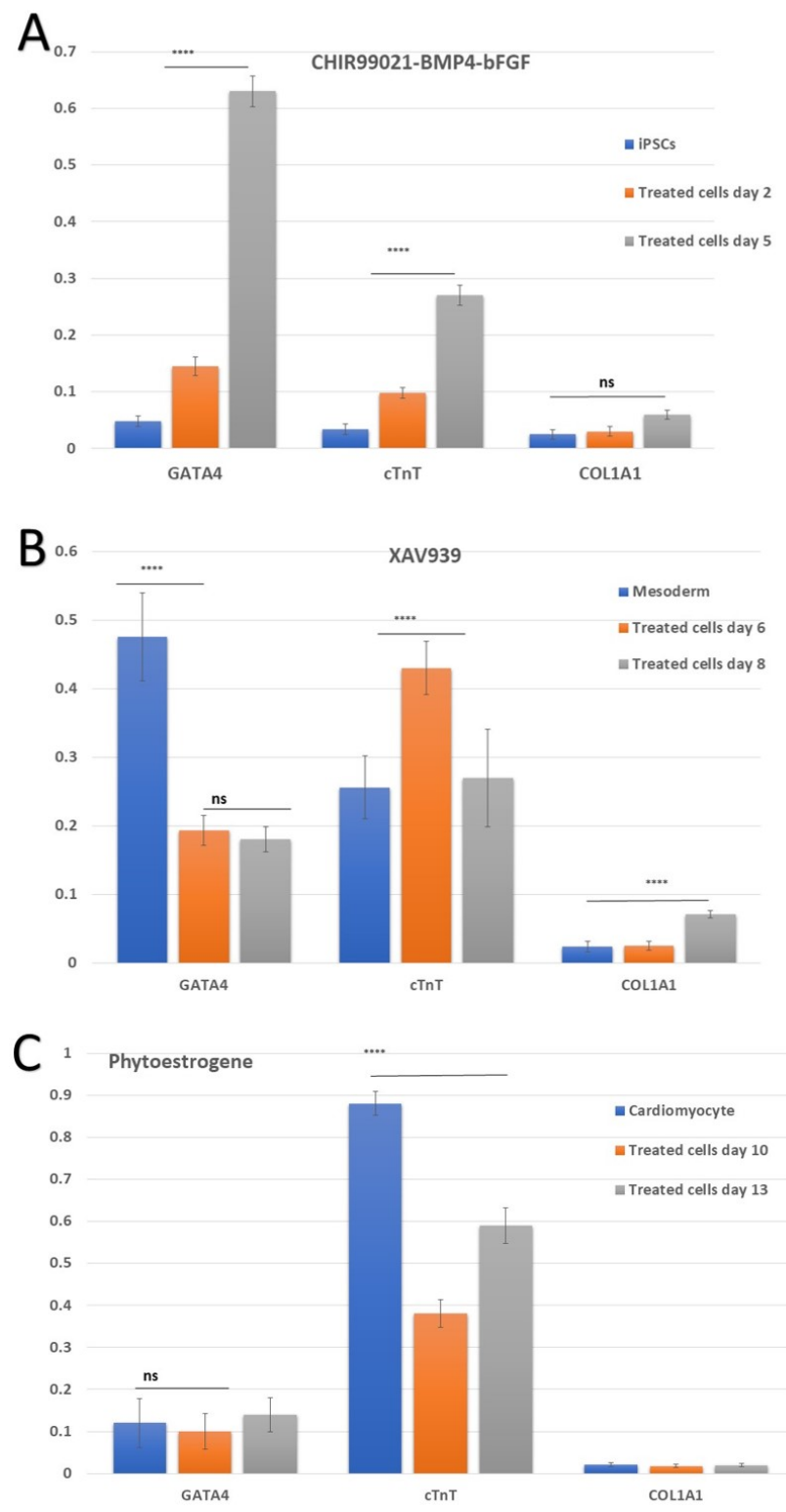

Fig. 4. Comparison of specific cardiac gene expression in all remedies and control group after treatment. (A) The addition of CHIR99021-BMP4-bFGF cocktail significantly increased the expression of mesoderm-related gene GATA-4 ( $p=0.003)$ compared to the control on day 2 and iPSCs, but the concentration of cardiomyocyte-associated gene $c \operatorname{Tn} T$ was relatively low ( $p=$ 0.009 ) and the expression of bone-related gene CollA1 is negligible. (B) On the day 6-8 of differentiation, the addition of XAV939 upregulated $c T n T$ and downregulated GATA-4 markers ( $p=0.018)$. (C) After the addition of phytoestrogen extract until day13, $c \operatorname{Tn} T$ gene expression increased significantly compared to day $6(p<0.01) .{ }^{* * * *}$ Significant; ns, non-significant.

diomyocytes that is suitable for clinical applications. In our study, the ability of some chemically small molecules, including those involved to activate WNT signaling pathway as well as plant-derived extracts, such as red clover leaves

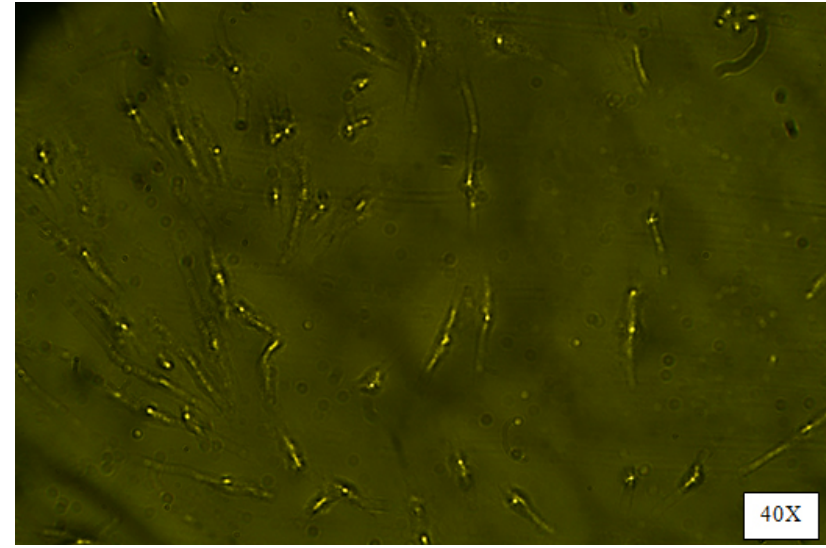

Fig. 5. Immunofluorescence staining of $\alpha$-actinin in day 13 after treatment with the small molecules and phytoestrogen.<smiles>O=c1c2cccc(-c3ccc(O)c(O)c3O)cc3c(O)c(O)c1c-3co2</smiles>

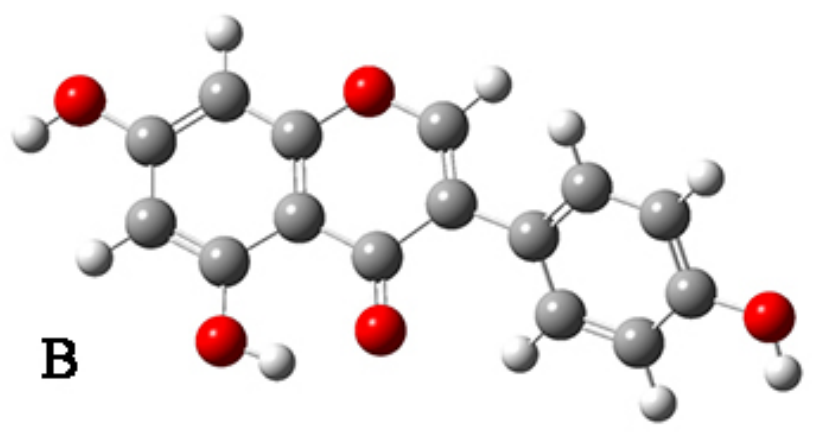

Fig. 6. The structural properties of genistein. (A) Twodimensional genistein molecular structure. (B) The theoretical geometric structure of genistein. Three-dimensional and optimal structure of genistein for molecular docking assay in MVD software package.

to target differentiation of cardiomyocytes were evaluated. To achieve this goal, sequential analysis was performed to determine the toxicity and lethal concentrations of small molecules and herbal extracts. We found that the appropriate dose of small molecules and plant extract induces the expression of cardiomyocyte target genes in iPSCs-derived cardiomyocytes. It was shown that $\mathrm{p} 38 \mathrm{MAPK}$ inhibitors can directly affect the fate of pluripotent stem cell differen- 


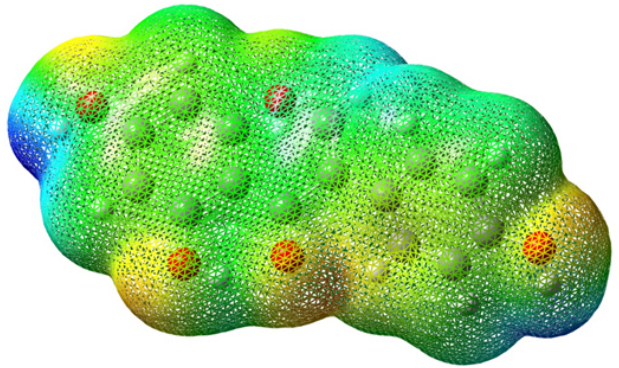

Electronic density range

Fig. 7. The molecular electrostatic potential (MEP) graph of genistein. The potential of the blue, green, and red regions of the molecular electrostatic potential (MEP) graph of genistein is positive, zero, and negative, respectively.

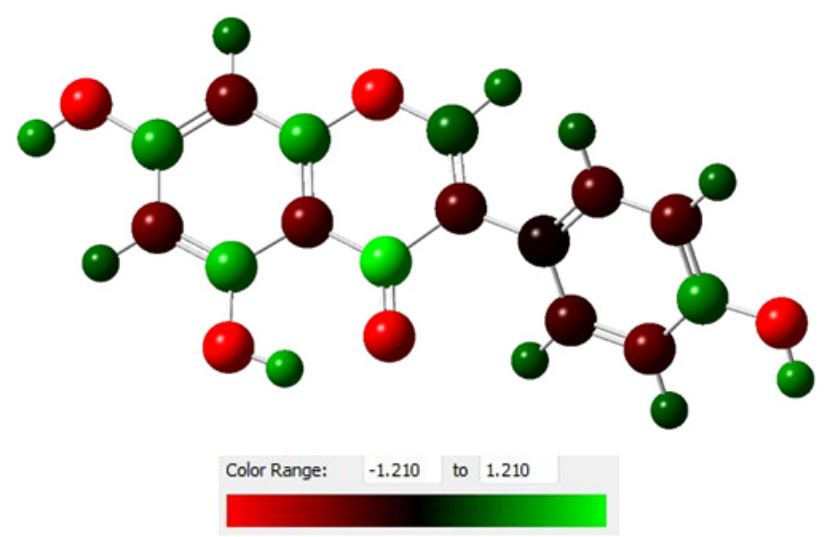

Fig. 8. The charge distribution of genistein. The red, black, and green loops show the high-electron, natural, and low-electron regions of genistein, respectively.

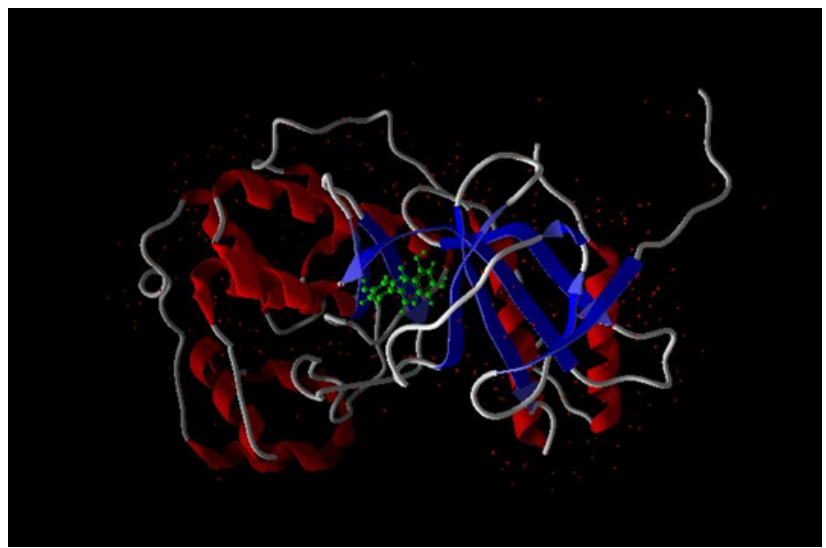

Fig. 9. Genistein (green ligand) inserted in the functional sites of p38MAPK.

tiation into mesoderm lineages and then, differentiate them into cardiac precursors and overexpress cardiomyocyterelated genes. Regulating WNT endogenous signaling pathway is critical for fetal heart development, in vitro dif- ferentiation of cardiomyocytes, and the treatment of heart disease [45]. Based on previous studies [42], WNT signaling pathway may be suitable for the production of cardiomyocytes and their sufficient differentiation. During stimulation of WNT signaling pathway, a combination of high concentrations of Activin A and low concentrations of BMP4 and bFGF in the early stages of mesoderm formation and increased cardiac mesoderm specificity is crucial [33]. Increasing evidence suggests that the interaction between the WNT and BMP signaling pathways as the most major multifunctional proteins plays a pivotal role to control the expression of genes involved in cardiac differentiation such as Nkx2-5, Isll, Gata4, Mef2c, and Baf60c, which ultimately leads to cardiac system evolution [34]. The production of efficient mesoderm lineages requires activating BMP signaling pathways and establishing proper $\mathrm{WNT} / \beta-$ catenin signaling coordination [30]. While, WNT signaling is still active, BMP4 growth factor can be used. BMP4 led to differentiate MSCs into the mesoderm, induced by a direct effect on the distal-less homeobox-5 (mDlx5) gene which is the main target gene for the BMP4 signaling pathway. Increased BMP4 levels are essential for the overexpression of genes involved in cardiomyocyte generation including Gata 4 and Nkx2-5. Furthermore, it was shown that basic fibroblast growth factor (bFGF) leads to increased expression of cardiac genes $\alpha-M H C$ and $\beta-M H C$ [46]. Therefore, based on our previous study, in order to achieve the appropriate concentration, a concentration series of bFGF was added to the culture medium by cardiomyocte differentiation method. As mentioned earlier, activating WNT signaling pathway is essential for mesoderm differentiation. Plant derivatives such as phytoestrogens, as a hormone similar to the female estrogen hormone, were very effective to produce the cardiomyocytes.

The affinity of estrogen to bind $\mathrm{ER} \alpha$ and $\mathrm{ER} \beta$ receptor, as a nuclear dimer protein, that binds to DNA and directs the expression of specific genes is high in cardiomyocytes. On the other hand, estrogen reduces producing free radicals and ROS, resulting in the inhibition of mitochondrial permeability by activating ERK signaling pathway. In addition to playing an important role to reduce the cardiomyopathy, estrogen also simultaneously reduces unwanted programmed cell death or apoptosis [47]. Therefore, we assayed the potential effects of phytoestrogens, such as herbal-xenoestrogen that imitates estrogen at the lowest optimum concentration $(1 \mathrm{nM})$. During our experiment, serial concentration of phytoestrogen extract was used, which was the appropriate and optimal concentration for the differentiation of cardiomyocytes on days 8 13 , while other proposed concentrations, 5,7 and $10 \mathrm{nM}$, no significant differentiation was observed and the cells did not acquire the proper morphology. Therefore, it was decided to use only $1 \mathrm{nM}$ to repeat the experiment. Red clover is one of the plants, in which different types of phytoestrogens such as daidzin and Genistein are found in abundance, 


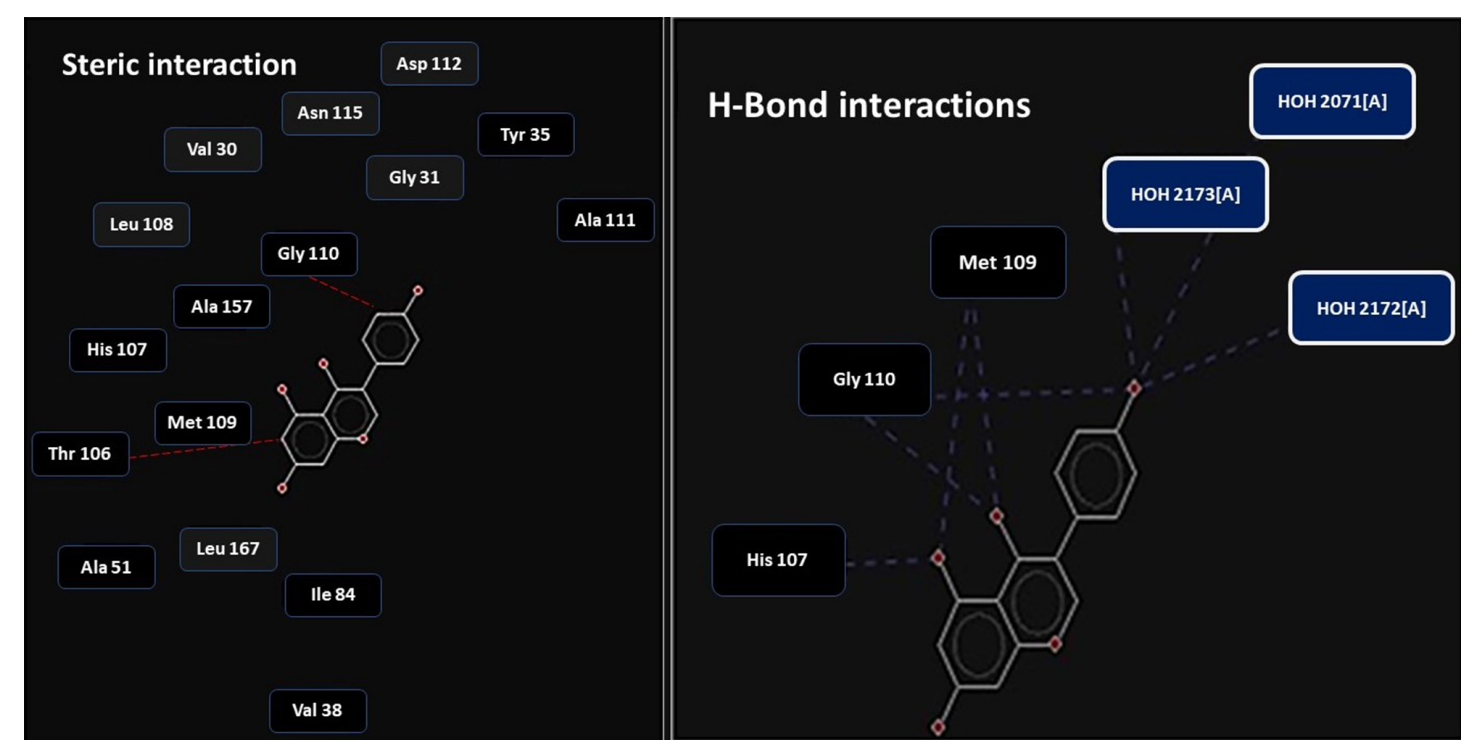

Fig. 10. H-Bond and steric interactions of genistein inserted in the functional site of p38MAPK.

all of which have estrogen-like properties and a high affinity for the $\operatorname{ER} \beta$ receptor [48]. The results of our previous studies represented that red clover leaf extract at the concentrations of 1-10 $\mathrm{nM}$ could be promising to determine the fate of MSC differentiation into cardiac precursor cells [42]. In this experiment, we showed that the expression of cardiomyocyte-specific genes, such as $c T n T$, increased when phytoestrogens were used. An appropriate concentration of $5 \mu \mathrm{M}$ CHIR990021 with phytoestrogen has a synergistic effect. This confirms our previous report on the role of phytoestrogens to activate WNT pathway signaling. In other words, applying $1 \mathrm{nM}$ phytoestrogen on days 6 to 13 along with XAV 939 have potential effects on the expression of cardiomyocyte-specified genes such as cTnT as well as appropriate morphology (Fig. 2).

We used small molecule CHIR99021 to quantitatively assess the level of WNT signaling and identify WNT activating capabilities. We found that $5 \mu \mathrm{M}$ CHIR99021 strongly activates WNT signaling pathway by day 5. During the first stage of differentiation into mesoderm lineage (0-5 days), the expression of GATA-4 marker compared to human induced pluripotent stem cells (hiPSCs), as a positive control, significantly increased $(p=0.003)$. Moreover, we used XAV939 to investigate the ability of small molecules to inhibit WNT. Based on the results of previous studies [49], we used $10 \mu \mathrm{M}$ concentration of XAV939 for our experiment. Based on our test, XAV939 inhibits WNT inhibition without apoptosis or severe programmed cell death. To induce cardiomyocytes properly, we decided to apply different combinations of growth factors and small molecules which regulate the signaling pathways such as TGF- $\beta$ (BMP4 and Activin A), bFGF, and WNT signaling pathway (CHIR99021, XAV939), as well as plant extracts containing phytoestrogens. Based on this analysis, we found that a combination of BMP4 $(25 \mathrm{ng} / \mathrm{mL}), \mathrm{bFGF}$
(100 ng/mL), and CHIR99021 (5 $\mu \mathrm{M})$ increased the expression of mesoderm genes such as GATA-4. Moreover, the nuclear and spindle appearance of cardiac cells observed in the final days (day 13) of differentiation. After the end of treatment, the cell is fixed by $4 \%$ glutaraldehyde coated with gold $(15 \mathrm{~nm})$ to be visualized by electron microscopy. As shown in Fig. 3, the extensive sarcomeric integrity filaments and centrally located double nucleated cells were observed in nearly 70-80 percent of total cells. After 13 days, when the cells cultured and differentiated in petri dish, they were harvested by a needle under the invert microscopy and fixed with $4 \%$ paraformaldehyde for SEM microscopy. SEM (FEI ESEM QUANTA 200 microscopy, FEI Co., Hillsboro, OR, USA) was performed in Partorayan Rastak Lab (Tehran, Iran). We found that creating a suitable substrate as an extracellular matrix (ECM) which mimics cardiac tissue conditions, together with the optimal concentration of growth factors and chemically and naturally small molecule compounds can be effective in generating induced pluripotent stem cell-derived cardiomyocytes. Besides, highly precise and subtle molecular methods, including quantitative-PCR were used to identify factors associated with in vitro cardiogenesis. We analyzed gene expression profiles in cardiac cells in the early (0-5 days) and the late stages (5-8) of cardiomyocyte differentiation in the presence of XAV939 and herbal extract phytoestrogens, respectively. The expression of genes involved in cardiogenesis, including Gata-4, cTnT compared to COL1A1, as mesenchymal and osteocyte control marker, and $G A P D H$, as a housekeeping gene, was assessed. mRNA expression levels were tested by reverse transcription-polymerase chain reaction (RT-qPCR) in treated cells. $\triangle \mathrm{Rn}$ data related to fluorescence severity in each PCR cycle were exported and analyzed in LinReg PCR software to obtain Cq or the CT value per sample to compare the CT values of control group. The 
induction of induced pluripotent stem cells into mesoderm lineages was executed using WNT signaling pathway stimulators on days $0-5$. For mesoderm induction, we tested the ability of CHIR99021 (5 $\mu \mathrm{M})$, BMP4 (25 ng/mL), and bFGF (100 ng/mL). For cardiomyocyte generation at the early stage on days 5-8, we used XAV939 $(10 \mu \mathrm{M})$, as a WNT signaling inhibitor, and at the late stage on days 8-13, we used phytoestrogen ( $1 \mathrm{nM})$, as an herbal extract cardiogenic stimulator. XAV939 is known as the small molecule inhibitor of WNT signaling pathway which indicated its ability by binding to tankyrase (TNKS) catalytic poly-ADPribose polymerase (PARP) domain. As shown in Fig. 4, the expression level of heart-related genes such as cTnT in comparison with mesoderm lineage, as a positive control, significantly increased $(p=0.009)$. GATA-4 is one of the important genes involved in the formation of mesoderm lineages that decreased during cardiac differentiation but increased during mesoderm differentiation $(p=0.018)$. The frequency of $c \operatorname{Tn} T$ gene expression was measured early on day 5 . While the addition of plant extracts containing phytoestrogens that mimic female estrogens increased the expression of cTnT markers. The addition of phytoestrogens within 8 days at an optimal concentration of $1 \mathrm{nM}$ along with a suppressor of the WNT signaling pathway leads to the differentiation of cardiomyocyte and the expression of cardiac-related markers compared to cardiomyocyte on day $10(p<0.01)$. Finally, we also detected $\alpha$-actinin (sarcomeric marker) by using immunostaining. Primary antibody against $\alpha$-actinin was stained with Alexa Flour ${ }^{\circledR} 488$ FITC conjugated secondary antibody on day 13. As shown in Fig. 5, the picture was captured by fluorescence microscope at $40 \times$ magnification.

The computational molecular docking (MD) methods were performed to investigate the structural properties and interaction of suitable amino acids of p38MAPK protein with small molecule genistein. One of the most important phytoestrogens extracted from red clover leaves is genistein. It was shown that this compound plays an important role to suppress p38MAPK expression, leading to a decrease in TGF $\beta$ signaling pathway and inhibiting the crosstalk between WNT and TGF $\beta$ signaling pathways [50]. As a result, the process of cardiomyocyte production from mesoderm lineage and eventually, cardiogenesis increases [51].

Genistein with IUPAC name 5,7-Dihydroxy3-(4-hydroxyphenyl) chromen-4-one or 4,5,7Trihydroxyisoflavone and with chemical formula $\mathrm{C}_{15} \mathrm{H}_{10} \mathrm{O}_{5}$ is an extracted chemical compound which is used as an inhibitor of the p38MAPK kinase. As shown in the molecular structure of genistein, this small molecule consisting of three saturated and unsaturated rings (Fig. 6A). Since this molecular compound is composed of several rings and elements and electrons are scattered in all parts of the structure, we evaluated different parts of genistein. DFT method at B3LYP/6-31++G $(\mathrm{d}, \mathrm{p})$ level of theory was used to optimally evaluate the structural properties of genistein. Fig. 6B indicates the optimized molecular structure of genistein. The potential of blue, green, and red regions of the molecular electrostatic potential (MEP) graph (Fig. 7) of genistein is positive, zero, and negative, respectively. Therefore, the carbonyl and amino groups of the genistein compound have the highest and the lowest electrostatic potential, respectively. Each region of genistein compound is more negative, has a higher electron density, and vice versa. The high-electron regions of genistein will interact with the low-electron regions of the active site of $\mathrm{p} 38 \mathrm{MAPK}$, and the low-electron region of genistein will interact with the high-electron regions of the active site of $\mathrm{p} 38 \mathrm{MAPK}$.

The natural population analysis (NPA) of the genistein chemical compound is acquired via Mulliken population analysis (MPA) using DFT method at the B3LYP/6$311++\mathrm{G}(\mathrm{d}, \mathrm{p})$ level of theory [52]. Fig. 8 indicates the charge distribution on the molecular structure of genistein. The red, black, and green loops show the high-electron, natural, and low-electron regions of genistein. The more negative the electric charge of genistein, the greater the tendency of atoms to interact with low electron regions of the active site of p38MAPK. Natural regions of genistein are capable of binding to $\mathrm{p} 38 \mathrm{MAPK}$ by the steric interactions. The lowelectron and high-electron regions of genistein are capable of binding to corresponding proteins by hydrogen bonds.

Molecular docking bioinformatics tools were also used to predict the binding orientation, activity, and affinity rate of the small molecule to corresponding proteins. The binding interaction of small molecules with associated proteins was performed using Molegro Virtual Docker (MVD) software package. Fig. 9 indicates the best interaction of genistein with the active site of p38MAPK. The extracted compound (ligands) was docked in the functional sites of p38MAPK, and the minimum energy (molecular docking score) was evaluated. In Table 2, some essential data obtained from molecular docking analysis including steric, hydrogen bond, electrostatic, water-ligand, torsional strain, total internal and external interactions are presented. Steric interactions are the most important protein-ligand interactions. The rate of total interaction between genistein and p38MAPK due to molecular docking score is -100.810 $\mathrm{Kcal} / \mathrm{mol}$, the interaction values above $-150 \mathrm{Kcal} / \mathrm{mol}$ are very strong, and values below -80 are very weak.

Based on Table 3, genistein binds to the residues Gly110, Val 30, Tyr 35, Met 109, Ala 108, Val38, Leu167, Ala51, Ile84, Gly31, Thr106, Ala157, Asn115, and Asp112 from the p38MAPK protein. Fig. 10 shows the most important amino acid residues of $\mathrm{p} 38 \mathrm{MAPK}$ protein with the steric interactions with genistein. Moreover, genistein is capable of binding to $\mathrm{p} 38 \mathrm{MAPK}$ via hydrogen bond (H-bond) interactions with the residues Met109, Gly110, and His107 from $\mathrm{p} 38 \mathrm{MAPK}$ protein and three water molecules $\mathrm{HOH}$ 2173, HOH 2071, and HOH 2172. 
Table 2. Moleclar docking data ftom interaction between genistein and p38MAPK.

\begin{tabular}{llc}
\hline Interactions & & MD score $(\mathrm{Kcal} / \mathrm{mol})$ \\
\hline & Steric (by PLP) & -98.985 \\
& Hydrogen bonds & -10.835 \\
External ligand & Electrostatic (short range) & 0.000 \\
interactions & Electrostatic (long range) & 0.000 \\
& Water-Ligand Interactions & -15.455 \\
& Total External interactions & -123.459 \\
\hline \multirow{4}{*}{ Internal ligand } & Torsional strain & 0.000 \\
interactions & Steric (by PLP) & 22.648 \\
& Hydrogen bonds & 0.000 \\
& Electrostatic & 0.000 \\
& Total Internal interactions & 22.648 \\
\hline \multicolumn{2}{l}{ Total interactions } & -100.810 \\
\hline
\end{tabular}

Table 3. The participated residues of p38MAPK in ligand-protein interactions.

\begin{tabular}{lc}
\hline Residue & MD score $(\mathrm{Kcal} / \mathrm{mol})$ \\
\hline Gly 110 & -15.839 \\
Val 30 & -13.209 \\
Tyr 35 & -12.473 \\
Met 109 & -10.927 \\
Ala 111 & -9.343 \\
Leu 108 & -8.142 \\
Val 38 & -6.440 \\
Leu 167 & -5.650 \\
Ala 51 & -5.511 \\
Ile 84 & -5.100 \\
His 107 & -4.931 \\
Water & -4.251 \\
Water & -4.048 \\
Water & -3.809 \\
Gly 31 & -2.210 \\
Thr 106 & -2.067 \\
Ala 157 & -1.605 \\
Water & -1.329 \\
Water & -1.105 \\
Asn 115 & -0.8536 \\
Asp 112 & -0.7477 \\
Water & -0.6169 \\
\hline
\end{tabular}

Furthermore, in molecular docking, some biochemical properties were examined regarding lipophilicity ( $\log$ $\left.\mathrm{P}_{O / W}: 1.91\right)$, water solubility ( $\log \mathrm{S}=-3.72:$ soluble), intestinal absorption (high), blood-brain barrier penetration (no), inhibitor of secondary metabolism (yes), skin permeability (yes, $\log \mathrm{K}_{P}=-6.05 \mathrm{~cm} / \mathrm{s}$ ), bioavailability via Lipinski's rules (yes, bioavailability score $=0.55$ ), and biocompatibility (yes).

\section{Discussion}

Previous studies showed that CVD rate in premenopausal women is significantly higher than in men and postmenopausal women which can be due to imbalances or fluctuations in estrogen production, and it was suggested that declined estrogen increased the risk of CVD $[53,54]$. Some of the plants are rich in isoflavones, such as red clover leaves, and contain some phytoestrogens, which can play a role similar to estrogen. The effect of these phytoestrogens on cardiomyocytes and the prevention of heart diseases has received much attention [55]. Furthermore, isoflavone interventions such as using genistein $(54 \mathrm{mg} /$ day) have also beneficial effects on osteogenesis and are safe in postmenopausal women [56]. Studies showed that phytoestrogens, such as genistein promote their potential functions by affecting estrogen receptor (ER)-mediated signaling pathway, the phospholipase $\mathrm{C}$, and mitogen-activated protein kinase (MAPK) [57]. Genistein undergoes phase II xenobiotic metabolism, such as glucuronidation and sulfation reactions at 7' and/or 4' positions of the isoflavone ring [58]. Based on the reports obtained from various studies, in the present study, it was decided to evaluate the possible effect of phytoestrogen-containing genistein on the differentiation of mesoderm lineage into cardiomyocytes along with other effective small molecules and growth factor.

Since CVD has become one of the most common causes of death in the world, finding promising and revolutionizing ways to treat heart-related diseases has become one of the most exciting and complex challenges in biomedical and regenerative medicine. In recent years, there were many advances in the treatment of heart disorders, but this disease is still recognized as the leading cause of mortality and morbidity around the world. Using pluripotent stem cells, such as ESC and iPSCs in the treatment of CVD has become a beneficial tool among medical biologists. Therefore, we decided to use the innovative differentiation protocol, which is less risky and more cost-effective. In the present study, small molecules and growth factors plus herbal-derived compounds were used to differentiate cardiomyocytes from iPSCs.

We initially used mouse embryonic fibroblasts (MEFs) feeder cells to maintain pluripotency and proliferation of iPSCs in a culture medium. Before we cultured iPSCs on feeder cells, MEFs cells were treated with mitomycin $\mathrm{C}$ antibiotic, by which MEFs were mitotically inactivated, but cells had metabolic activity. These types of cells provide and produce growth factors, such as Activin A, extracellular matrix, cytokines, and adhesion molecules. Recently, xeno-free cell culture protocols such as mTeSR have been used for the maintenance of iPSCs to avoid contamination with pathogens and animal factors. This method cannot be used on a large scale because the growth factors need to provide proliferation and they are not able to support undifferentiated stem cell growth. Therefore, their use on a large scale is not cost-effective due to the 
consumption of human serum albumin and growth factors.

The importance of using small chemical molecules as extrinsic stimuli was proven in cardiomyocyte generation and pluripotent stem cell differentiation. At the first stage of differentiation ( $0-5$ days), the formation of mesodermal cells, using small molecules, such as CHIR99021 and growth factor bFGF, Activin A, and BMP4 activated the $\mathrm{WNT} / \beta$-catenin signaling pathway and this stage compared to hiPSCs, as a positive control, based on GATA-4 marker. GATA-4 marker in mesoderm lineage in comparison with hiPSCs significantly overexpressed. At the second stage of our experiment, for the formation of cardiomyocytes, the $\mathrm{WNT} / \beta$-catenin pathway as a small molecule inhibitor, such as XAV939 was added which increased the expression of a cardiomyocyte-associated marker, such as cTnT. In our studies, we showed that WNT signaling pathway induction by $5 \mu \mathrm{M}$ CHIR99021, $25 \mathrm{ng} / \mathrm{mL} \mathrm{BMP} 4$, and $100 \mathrm{ng} / \mathrm{mL}$ bFGF directly was involved in mesoderm differentiation. Also, 5-8 days after differentiation, for cardiomyocyte generation, the WNT signaling pathway was inhibited by $10 \mu \mathrm{M}$ XAV939 within 3 days. It seemed that BIO has a toxic impact on iPSCs. Finally, we added phytoestrogen to the culture medium containing differentiated cardiomyocyte for 5 days. After 13 days, our analysis indicated that appropriate cardiomyocyte induction required precise timing and proper concentrations. In this study, we found that insulin and ascorbic acid in culture medium has an important role in cardiomyocyte differentiation.

Finally, the chemical structure and the electric charge distribution of genistein were investigated, and the interaction of this compound with important amino acids of p38MAPK protein was studied using computational molecular docking bioinformatics assay. Furthermore, some key biomedical parameters, including lipophilicity, watersolubility, intestinal absorption, blood-brain barrier penetration, and biocompatibility were evaluated.

We found that although an optimal dose of small molecules and growth factors were executed in the early stages of mesodermal differentiation, the vital role of genistein phytoestrogen in cardiomyocyte differentiation was quite evident in the late stage after 13 days. Therefore, based on the results of our research, we found that phytoestrogens, somewhat like estrogen, are capable of playing an essential role in maintaining heart health.

\section{Conclusions}

Based on our results, XAV939, a novel inhibitor of Wnt/ $\beta$-catenin signaling pathway, and phytoestrogen extracted from the plant, are robustly capable of inducing cardiogenesis in human iPSCs. Based on the results of molecular docking bioinformatics assay, phytoestrogen genistein can be structurally and functionally a suitable compound for cardiomyocyte differentiation and showed that this small molecule is properly located in the functional site of p38MAPK protein which leads to inhibit it. Our cardiomyocyte differentiation procedure provides a reproducible platform that on the one hand, is cost-effective and, on the other hand, can be beneficial in reducing estrogeninduced CVD and provides a valuable source of cardiomyocyte for cellular reparative therapies and improves largescale pharmacological screening.

\section{Author contributions}

JK was contributed in experimental phase, manuscript writing, and figure design; HS, PP, MS were contributed in study designs, data analysis, manuscript revision.

\section{Ethics approval and consent to participate}

The study was a part of the main project approved by the research ethics committee of Iran National Institute for Medical Research Development on 2nd February 2019 with a reference number IR. NIMAD. REC.1398.051.

\section{Acknowledgment}

We deeply appreciate Zahra Azadian and Atefeh Alipour for their assistant in discussion, manuscript preparation and technical supports in the laboratory phase.

\section{Funding}

This research was partially supported by grant in aid from National Institute for Medical Research Development (NIMAD No. 973364) to HS.

\section{Conflict of interest}

The authors declare no conflict of interest.

\section{References}

[1] Lozano R, Naghavi M, Foreman K, Lim S, Shibuya K, Aboyans $\mathrm{V}$, et al. Global and regional mortality from 235 causes of death for 20 age groups in 1990 and 2010: a systematic analysis for the Global Burden of Disease Study 2010. Lancet. 2012; 380: 2095-2128.

[2] Sarrafzadegan N, Mohammmadifard NJAoIm. Cardiovascular disease in Iran in the last 40 years: prevalence, mortality, morbidity, challenges and strategies for cardiovascular prevention. Archives of Iranian Medicine. 2019; 22: 204-210.

[3] Wang H, Naghavi M, Allen C, Barber RM, Bhutta ZA, Carter $\mathrm{A}$, et al. Global, regional, and national life expectancy, all-cause mortality, and cause-specific mortality for 249 causes of death, 1980-2015: a systematic analysis for the Global Burden of Disease Study 2015. Lancet. 2016; 388: 1459-1544.

[4] Sawa Y. Surgical Regeneration Therapy Using Myoblast Sheets for Severe Heart Failure. Japanese Journal of Thoracic Surgery. 2017; 70: 9-13. (In Japanese)

[5] Murry CE, Reinecke H, Pabon LM. Regeneration gaps: observations on stem cells and cardiac repair. Journal of the American College of Cardiology. 2006; 47: 1777-1785.

[6] de Simone G, Devereux RB, Daniels SR, Meyer RA. Gender differences in left ventricular growth. Hypertension. 1995; 26: 979-983.

[7] Wake R, Yoshiyama M. Gender Differences in Ischemic Heart Disease. Recent Patents on Cardiovascular Drug Discovery. 2009; 4: 234-240. 
[8] Kararigas G, Dworatzek E, Petrov G, Summer H, Schulze TM, Baczko I, et al. Sex-dependent regulation of fibrosis and inflammation in human left ventricular remodelling under pressure overload. European Journal of Heart Failure. 2014; 16: 11601167.

[9] Naftolin F, Friedenthal J, Nachtigall R, Nachtigall LJF. Cardiovascular health and the menopausal woman: the role of estrogen and when to begin and end hormone treatment. F1000Research. 2019; 8: F1000 Faculty Rev-1576.

[10] Johansen N, Tonstad S, Liavaag AH, Selmer RM, Tanbo TG, Michelsen TM. Risk of cardiovascular disease after preventive salpingo-oophorectomy. International Journal of Gynecologic Cancer. 2020; 30: 575-582.

[11] Oka S-i, Sabry AD, Cawley KM, Warren JSJFicm. Multiple levels of PGC- $1 \alpha$ dysregulation in heart failure. Frontiers in Cardiovascular Medicine. 2020; 7: 2.

[12] Balafkan N, Mostafavi S, Schubert M, Siller R, Liang KX, Sullivan G, et al. A method for differentiating human induced pluripotent stem cells toward functional cardiomyocytes in 96well microplates. Scientific Reports. 2020; 10: 18498.

[13] Burridge PW, Keller G, Gold JD, Wu JC. Production of de novo cardiomyocytes: human pluripotent stem cell differentiation and direct reprogramming. Cell Stem Cell. 2012; 10: 16-28.

[14] Guan X, Xu W, Zhang H, Wang Q, Yu J, Zhang R, et al. Transplantation of human induced pluripotent stem cell-derived cardiomyocytes improves myocardial function and reverses ventricular remodeling in infarcted rat hearts. Stem Cell Research \& Therapy. 2020; 11: 73.

[15] Marzouni ET, Dorcheh SP, Nejad-Moghaddam A, Ghanei M, Goodarzi H, Hosseini SE, et al. Adipose-derived mesenchymal stem cells ameliorate lung epithelial injury through mitigating of oxidative stress in mustard lung. Regenerative Medicine. 2020; 15: $1861-1876$

[16] Ito M, Hara H, Takeda N, Naito AT, Nomura S, Kondo M, et al. Characterization of a small molecule that promotes cell cycle activation of human induced pluripotent stem cell-derived cardiomyocytes. Journal of Molecular and Cellular Cardiology. 2019; 128: 90-95.

[17] Sharma A, Li G, Rajarajan K, Hamaguchi R, Burridge PW, Wu SM. Derivation of highly purified cardiomyocytes from human induced pluripotent stem cells using small molecule-modulated differentiation and subsequent glucose starvation. Journal of Visualized Experiments. 2015; 52628.

[18] Singh VP, Pinnamaneni JP, Pugazenthi A, Sanagasetti D, Mathison M, Wang K, et al. Enhanced Generation of Induced Cardiomyocytes Using a Small-Molecule Cocktail to Overcome Barriers to Cardiac Cellular Reprogramming. Journal of the American Heart Association. 2020; 9: e015686.

[19] Liu Y, Chen B, Yang X, Fugate JA, Kalucki FA, FutakuchiTsuchida A, et al. Human embryonic stem cell-derived cardiomyocytes restore function in infarcted hearts of non-human primates. Nature Biotechnology. 2018; 36: 597-605.

[20] Hirschi KK, Li S, Roy K. Induced pluripotent stem cells for regenerative medicine. Annual Review of Biomedical Engineering. 2014; 16: 277-294.

[21] Sepac A, Si-Tayeb K, Sedlic F, Barrett S, Canfield S, Duncan $\mathrm{SA}$, et al. Comparison of cardiomyogenic potential among human ESC and iPSC lines. Cell Transplantation. 2012; 21: $2523-$ 2530.

[22] Hwang GH, Park SM, Han HJ, Kim JS, Yun SP, Ryu JM, et al. Purification of small molecule-induced cardiomyocytes from human induced pluripotent stem cells using a reporter system. Journal of Cellular Physiology. 2017; 232: 3384-3395.

[23] Ueno S, Weidinger G, Osugi T, Kohn AD, Golob JL, Pabon L, et $a l$. Biphasic role for $\mathrm{Wnt} / \beta$-catenin signaling in cardiac specification in zebrafish and embryonic stem cells. Proceedings of the
National Academy of Sciences of the United States of America. 2007; 104: 9685-9690.

[24] Desmarais JA, Unger C, Damjanov I, Meuth M, Andrews P. Apoptosis and failure of checkpoint kinase 1 activation in human induced pluripotent stem cells under replication stress. Stem Cell Research \& Therapy. 2016; 7: 17.

[25] An WF, Germain AR, Bishop JA, Nag PP, Metkar S, Ketterman J, et al. Discovery of potent and highly selective inhibitors of GSK3b. In Probe Reports from the NIH Molecular Libraries Program. National Center for Biotechnology Information (US). 2014.

[26] Huang T, Li L, Moalim-Nour L, Jia D, Bai J, Yao Z, et al. A Regulatory Network Involving $\beta$-Catenin, e-Cadherin, PI3k/Akt, and Slug Balances Self-Renewal and Differentiation of Human Pluripotent Stem Cells in Response to Wnt Signaling. Stem Cells. 2015; 33: 1419-1433.

[27] Tan JY, Sriram G, Rufaihah AJ, Neoh KG, Cao T. Efficient derivation of lateral plate and paraxial mesoderm subtypes from human embryonic stem cells through GSKi-mediated differentiation. Stem Cells and Development. 2013; 22: 1893-1906.

[28] Naujok O, Lentes J, Diekmann U, Davenport C, Lenzen S. Cytotoxicity and activation of the Wnt/beta-catenin pathway in mouse embryonic stem cells treated with four GSK3 inhibitors. BMC Research Notes. 2014; 7: 273.

[29] Yoshino Y, Ishioka C. Inhibition of glycogen synthase kinase3 beta induces apoptosis and mitotic catastrophe by disrupting centrosome regulation in cancer cells. Scientific Reports. 2015; 5: 13249.

[30] Lian X, Hsiao C, Wilson G, Zhu K, Hazeltine LB, Azarin SM, et $a l$. Robust cardiomyocyte differentiation from human pluripotent stem cells via temporal modulation of canonical Wnt signaling. Proceedings of the National Academy of Sciences of the United States of America. 2012; 109: E1848-E1857.

[31] Laco F, Woo TL, Zhong Q, Szmyd R, Ting S, Khan FJ, et al. Unraveling the Inconsistencies of Cardiac Differentiation Efficiency Induced by the GSK3 $\beta$ Inhibitor CHIR99021 in Human Pluripotent Stem Cells. Stem Cell Reports. 2018; 10: 18511866.

[32] Zhao M, Tang Y, Zhou Y, Zhang J. Deciphering Role of Wnt Signalling in Cardiac Mesoderm and Cardiomyocyte Differentiation from Human iPSCs: Four-dimensional control of Wnt pathway for hiPSC-CMs differentiation. Scientific Reports. 2019; 9: 19389.

[33] Kattman SJ, Witty AD, Gagliardi M, Dubois NC, Niapour M, Hotta A, et al. Stage-specific optimization of activin/nodal and BMP signaling promotes cardiac differentiation of mouse and human pluripotent stem cell lines. Cell Stem Cell. 2011; 8: 228240.

[34] Andersen P, Tampakakis E, Jimenez DV, Kannan S, Miyamoto $\mathrm{M}$, Shin HK, et al. Precardiac organoids form two heart fields via Bmp/Wnt signaling. Nature Communications. 2018; 9: 3140.

[35] Ulmer BM, Stoehr A, Schulze ML, Patel S, Gucek M, Mannhardt I, et al. Contractile Work Contributes to Maturation of Energy Metabolism in hiPSC-Derived Cardiomyocytes. Stem Cell Reports. 2018; 10: 834-847.

[36] Correia C, Koshkin A, Duarte P, Hu D, Carido M, Sebastião MJ, et al. 3D aggregate culture improves metabolic maturation of human pluripotent stem cell derived cardiomyocytes. Biotechnology and Bioengineering. 2018; 115: 630-644.

[37] Lemoine MD, Mannhardt I, Breckwoldt K, Prondzynski M, Flenner F, Ulmer B, et al. Human iPSC-derived cardiomyocytes cultured in 3D engineered heart tissue show physiological upstroke velocity and sodium current density. Scientific Reports. 2017; 7: 5464 .

[38] Machiraju P, Greenway SC. Current methods for the maturation of induced pluripotent stem cell-derived cardiomyocytes. World 
Journal of Stem Cells. 2020; 11: 33-43.

[39] Ahmed RE, Anzai T, Chanthra N, Uosaki HJFiC, Biology D. A brief review of current maturation methods for human induced pluripotent stem cells-derived cardiomyocytes. Frontiers in Cell and Developmental Biology. 2020; 8: 178.

[40] Iorga A, Cunningham CM, Moazeni S, Ruffenach G, Umar S, Eghbali $\mathrm{M}$. The protective role of estrogen and estrogen receptors in cardiovascular disease and the controversial use of estrogen therapy. Biology of Sex Differences. 2017; 8: 33.

[41] Morito K, Hirose T, Kinjo J, Hirakawa T, Okawa M, Nohara T, et al. Interaction of phytoestrogens with estrogen receptors alpha and beta. Biological \& Pharmaceutical Bulletin. 2001; 24: 351356.

[42] Azadian Z, Shafiei M, Hosseini S, Kazemi J, Alipour A, Shahsavarani H. EfficientIn VitroDifferentiation of Adipose TissueDerived Mesenchymal Stem Cells into the Cardiomyocyte Using Plant-Derived Natural Compounds. Proceedings of the Singapore National Academy of Science. 2019; 13: 47-63.

[43] Parikh A, Wu J, Blanton RM, Tzanakakis ES. Signaling Pathways and Gene Regulatory Networks in Cardiomyocyte Differentiation. Tissue Engineering Part B, Reviews. 2015; 21: $377-$ 392.

[44] Liu Q, Van Bortle K, Zhang Y, Zhao M, Zhang JZ, Geller BS, et al. Disruption of mesoderm formation during cardiac differentiation due to developmental exposure to 13-cis-retinoic acid. Scientific Reports. 2018; 8: 12960

[45] Ozhan G, Weidinger G. Wnt $/ \beta$-catenin signaling in heart regeneration. Cell Regeneration. 2015; 4: 3.

[46] Hatami L, Valojerdi MR, Mowla SJ. Effects of oxytocin on cardiomyocyte differentiation from mouse embryonic stem cells. International Journal of Cardiology. 2007; 117: 80-89.

[47] Morselli E, Santos RS, Criollo A, Nelson MD, Palmer BF, Clegg DJ. The effects of oestrogens and their receptors on cardiometabolic health. Nature Reviews. Endocrinology. 2017; 13: 352-364.

[48] Tava A, Pecio Ł, Lo Scalzo R, Stochmal A, Pecetti L. Phenolic Content and Antioxidant Activity in Trifolium Germplasm from Different Environments. Molecules. 2019; 24: 298.

[49] Minami I, Yamada K, Otsuji TG, Yamamoto T, Shen Y, Otsuka $\mathrm{S}$, et al. A small molecule that promotes cardiac differentiation of human pluripotent stem cells under defined, cytokine- and xeno-free conditions. Cell Reports. 2012; 2: 1448-1460.

[50] Shi Y, Zhang X, Hu Z, Zhang C, Liao D, Huang H, et al. Genistein Protects $\mathrm{H} 9 \mathrm{c} 2$ Cardiomyocytes against Chemical HypoxiaInduced Injury via Inhibition of Apoptosis. Pharmacology. 2019; 103: 282-290.

[51] Dixit P, Katare R. Challenges in identifying the best source of stem cells for cardiac regeneration therapy. Stem Cell Research \& Therapy. 2015; 6: 26.

[52] Abraham CS, Prasana JC, Muthu S, Rizwana B F, Raja M. Quantum computational studies, spectroscopic (FT-IR, FT-Raman and UV-Vis) profiling, natural hybrid orbital and molecular docking analysis on 2,4 Dibromoaniline. Journal of Molecular Structure. 2018; 1160: 393-405.

[53] Anagnostis P, Paschou SA, Katsiki N, Krikidis D, Lambrinoudaki I, Goulis DG. Menopausal Hormone Therapy and Cardiovascular Risk: where are we now? Current Vascular Pharmacology. 2019; 17: 564-572.

[54] Pu D, Tan R, Yu Q, Wu J. Metabolic syndrome in menopause and associated factors: a meta-analysis. Climacteric : the Journal of the International Menopause Society. 2017; 20: 583-591.

[55] Wolters M, Dejanovic GM, Asllanaj E, Günther K, Pohlabeln $\mathrm{H}$, Bramer WM, et al. Effects of phytoestrogen supplementation on intermediate cardiovascular disease risk factors among postmenopausal women: a meta-analysis of randomized controlled trials. Menopause. 2020; 27: 1081-1092.

[56] Sansai K, Na Takuathung M, Khatsri R, Teekachunhatean $\mathrm{S}$, Hanprasertpong N, Koonrungsesomboon N. Effects of isoflavone interventions on bone mineral density in postmenopausal women: a systematic review and meta-analysis of randomized controlled trials. Osteoporosis International. 2020; 31: $1853-1864$.

[57] Liu A, Zhang D, Yang X, Song Y. Estrogen receptor alpha activates MAPK signaling pathway to promote the development of endometrial cancer. Journal of Cellular Biochemistry. 2019; 120: 17593-17601.

[58] Hosoda K, Furuta T, Yokokawa A, Ishii KJA, chemistry b. Identification and quantification of daidzein-7-glucuronide-4'sulfate, genistein-7-glucuronide-4'-sulfate and genistein-4', 7diglucuronide as major metabolites in human plasma after administration of kinako. Analytical and Bioanalytical Chemistry. 2010; 397: 1563-1572. 